\title{
RELATIONSHIP BETWEEN FAMILIARITY, ATTITUDES AND PREFERENCES: ASSISTED LIVING FACILITIES AS COMPARED TO NURSING HOMES
}

(Accepted 17 October 2005)

\begin{abstract}
In this paper, the authors aim to (a) explore attitudes toward and preferences for living in the newly emerging place type of assisted living facilities in comparison to nursing homes, and (b) assess the possible impact of familiarity on those attitudes and preferences. Ninety-eight respondents (with a mean age of 62) were surveyed. Respondents were found to be more favorable toward assisted living facilities than nursing homes. A three-factor model was proposed in which attitudes mediated between familiarity and preferences. Increased familiarity seemed to predict enhanced favorable attitudes in the case of assisted living facilities, as opposed to unfavorable attitudes in the case of nursing homes. However, positive attitudes seemed to predict preferences for living in either place type. Results are discussed with regards to the literature on the mere exposure effect and long-term care for older adults.
\end{abstract}

KEY WORDS: assisted living, attitudes, familiarity, mere exposure effect, nursing home, preferences

\section{INTRODUCTION}

There is a growing and pressing need to provide accommodation alternatives for an aging population (Hauser, 1976; Grundy, 1983). This need to develop alternative care facilities first directed state bureaucracies toward the available medical model, which led to the design of nursing homes (Schwarz, 1999). However, nursing homes in general were not considered conducive to meeting the multidimensional needs of older adults in different countries (Johnson and Grant, 1985; Imamoğlu and Imamoğlu, 1992; Imamoğlu and Kilı̧, 1999; Schwarz, 1999; French and Mosher-Ashley, 2000; Kane, 2001). Still, factors such as the quality of the services provided (Carp, 1966; Lawton and Cohen, 1974; Imamoğlu and Kılıç, 1999), voluntary 
relocation (Schooler, 1976; Rowland, 1977), and personal control (Langer and Rodin, 1976; Schulz, 1976; Rodin and Langer, 1977; Schulz and Hanusa, 1980; Slivinske and Fitch, 1987) were found to influence older adults' outlook toward institutional living in a favorable direction. Hence, older adults and their families have been pushing providers to change existing settings to reflect a more appealing and homelike quality (Schwarz, 1999). In response to such demands, new place types emerged under different names (e.g., board and care homes, personal care homes, group homes, close care), which generally are referred to as assisted living facilities (e.g., Schwarz and Brent, 1999; Habell, 2001). Thus, the aim of the present study was (a) to explore attitudes and preferences for this newly emerging place type, assisted living facilities, in comparison to nursing homes, and (b) to assess the possible impact of familiarity on those attitudes.

In the related literature, assisted living facilities are generally treated as aiming to provide flexible care to meet the needs of individuals with differing levels of disabilities at homelike settings involving such attributes as privacy, dignity, choice, independence, individuality and homelike surroundings (Wilson, 1990; Regnier, 1994; Brummett, 1997; Ball et al., 2000; Dobbs, 2004). In a similar vein, advertisements of assisted living claim to provide individualistic service in residential settings (Imamoğlu, 2002, unpublished).

The above-noted reports seem to regard assisted living as an answer to public demands for emotionally acceptable living alternatives for older adults. Furthermore, some experts claim that there is increasing demand for assisted living in the market (Zimmerman, 2000; Becker et al., 2002). In spite of such positive claims, however, the term assisted living has been said to be "ambiguous, confusing and controversial" (Schwarz, 1999, p. 190), and difficult to define (Kane and Wilson, 1993; Mollica et al., 1995). The public seems to be expressing concerns about assisted living facilities turning into "mirror images of nursing homes" (Steinhauer, 2001) or "becoming mini nursing homes" (Zahn, 2001). There are reports underlining the need for policy makers to evaluate how assisted living programs affect quality of life (Sheehan and Oakes, 2003). Thus, there seems to be some confusion regarding the exact nature of the attitudes toward assisted living and uncertainty as to how those attitudes may change over time as people become more familiar with them. 
Accordingly, the aim of the present study was to shed light on the relationships between (a) favorability of attitudes (i.e., affectivecognitive representations) toward assisted living facilities and nursing homes, (b) preferences (i.e., intentions to live in them in the future), and (c) the degree of familiarity with each place type. By extrapolating from the possible impact of familiarity on attitudes and preferences, it was considered that it might be possible to make predictions about future trends for these living alternatives.

The respondents' attitudes were expected to be more favorable about living in an assisted living facility than a nursing home. This expectation was based on past findings, which indicate attitudes toward institutional living to be more unfavorable than those toward other alternatives such as sheltered housing or assisted care (Imamoğlu and Imamoğlu, 1992; French and Mosher-Ashley, 2000). In line with those findings, the limited research on assisted living facilities indicates that their residents express favorable views about such facilities (Zavotka and Teaford, 1997; Ball et al., 2000; Dobbs, 2004).

Furthermore, favorability of assisted living was expected to be positively associated with increased familiarity. This latter prediction was based on the mere exposure effect, which states that the more people are exposed to an initially unobjectionable stimulus, the more they would like it (Zajonc, 1968). Empirical research across cultures and diverse stimulus domains have shown that repeated-exposure can in and of itself enhance positive affect (Bornstein, 1989; Zajonc, 2001). For example, experimental studies have demonstrated that increasing exposure to images of female faces increases their attractiveness (Peskin and Newell, 2004). In a similar vein, in a field experiment conducted at a college classroom setting, students rated female research confederates more positively on measures of liking and attractiveness, the more often they had seen them in their classroom, even though they had never interacted with them (Moreland and Beach, 1992). Although, to our knowledge, the mere exposure effect has not been applied to place types before, increased familiarity with assisted living facilities was expected to have a positive impact on both the favorable affective-cognitive components of attitudes (i.e., stronger homelike representations, positive impressions), and preferences (i.e., behavioral inclinations to live in them in the future).

On the other hand, just the opposite association was predicted for nursing homes, which generally are seen as unpleasant (e.g., 
Imamoğlu and Imamoğlu, 1992; French and Mosher-Ashley, 2000; Kane, 2001; Imamoğlu, 2002, unpublished). This prediction was based on the limitation of the mere exposure effect to stimuli that are initially perceived as pleasant or at least neutral. In other words, the effect does not seem to work for people or objects initially perceived as negative, for which just the opposite may be observed (e.g., Perlman and Oskamp, 1971; Swap, 1977). Accordingly, increased familiarity with nursing homes was expected to be associated with even more unfavorable attitudes (i.e., stronger institutional, weaker homelike representations), and weaker preferences to live in them in the future.

\section{METHODS}

\section{Sample}

Ninety-eight respondents ( 72 females, 26 males), with a mean age of 62 participated in the study. Respondents were recruited from senior resource centers, retired persons' groups, Community Opportunities Club for the disabled, Milwaukee County Department on Aging staff, University of Wisconsin-Milwaukee staff and through social contacts from the Milwaukee area in the United States. One consideration in selecting respondents was to make sure that they knew what an assisted living facility is.

Educational level of the respondents ranged from grade school or some years at high school (1) to having graduate degrees (5), the mean schooling being 3.4, which implies that the average level of education involved attending college or university. In terms of current employment status, $32 \%$ of the respondents were full time, $15 \%$ part-time employed, whereas $42 \%$ were retired. The remaining $10 \%$ were not employed at the time. Their occupations were quite variable, involving teachers, social workers, housewives, and so on. As for their living arrangements, an overwhelming majority of the respondents $(91 \%)$ were living in their own houses or apartments; some with their families or with health care service at home.

\section{Questionnaire}

The data for the present paper were collected as part of a larger questionnaire study about place schemas. Apart from the questions 
and indices explained below, data were obtained about demographic characteristics of the respondents (e.g., age, gender, educational status, current living arrangements, occupation and current work status).

\section{Familiarity with Places}

Respondents were asked to specify the degree to which they felt familiar with assisted living and nursing homes on 5-point scales ( $1=$ very familiar; $5=$ not at all familiar). Assisted living and nursing homes were presented with six other place types, some of which were well established (e.g., school, hospital, a homelike place, an institutional place), whereas some were newly emerging (e.g., co-housing, cyber-café).

\section{Homelike and Institutional Place Representations}

Respondents were provided with five homelike and five institutional place descriptions prepared by the first author on the basis of the related literature (e.g., Gubrium, 1975; Wilson, 1990; Kane and Wilson, 1993; Marsden, 1999; Schwarz and Brent, 1999; for a review, see Day et al., 2000). For example, homelike descriptions included, "In this place, if one desires to get away from others, it is possible..." and "...one can make one's own schedules..."; whereas those for institutional places involved such descriptions as "Because this place accommodates a large number of people, one might feel isolated...", “... going to one's bedroom requires walking through a long corridor with identical doors on both sides". Respondents were asked to indicate the degree to which each description was similar to or different from their conceptions of assisted living, home, and nursing home on 5 -point scales $(1=$ very similar; $5=$ very different $)$. Cronbach's $\alpha$ for the homelike index were 0.75 and 0.66 for assisted living and nursing home, whereas they were 0.73 and 0.84 for the institutional index, respectively. These indices were found to provide valid measures for the related places (Imamoğlu, 2005, in preparation).

\section{Impressions of Assisted Living Facilities}

Respondents were asked to specify where they first came across the term/place "assisted living" and to rate their impressions of it on a 5 -point scale ( $1=$ very favorable; $5=$ very unfavorable) and to elaborate on their impressions. 


\section{Preferences for Living in Assisted Living Facilities, Home and Nursing Homes}

Respondents were asked to respond to the question, "In the future, how favorable or unfavorable would you feel about living in the places indicated below?" regarding an assisted living, their own homes or a nursing home, using 5 -point scales $(1=$ very favorable; $5=$ very unfavorable).

\section{Procedure}

Participation in the study was voluntary. Respondents were asked not to put their names on the questionnaires and were assured that their answers would be kept confidential. Almost all respondents completed the questionnaire forms at their meeting places, offices or homes by themselves. In rare instances, assistance was provided to certain older or disabled respondents to read the questions and to record their responses.

\section{RESULTS}

First, comparative results concerning familiarity with, attitudes toward, and preferences for assisted living facilities and nursing homes are reported. Then, intercorrelations and significant predictors of key variables, analyzed by structural equation modeling (SEM) separately for assisted living facilities and nursing homes, are presented and highlighted in the form of a three-factor model of relationships between familiarity, attitudes and preferences.

Familiarity with Assisted Living Facilities and Nursing Homes as Compared to Other Established or Newly Emerging Place Types

In the questionnaire, respondents indicated their degree of familiarity with assisted living, nursing homes and six other place types. Respondents were found to be "somewhat familiar" with assisted living $(M=3.08, \mathrm{SD}=1.16)$, and were relatively more familiar with nursing homes, $(M=2.60, \mathrm{SD}=1.33), t(97)=3.46, p<0.001$ (2-tailed). However, they were found to be more familiar with assisted living relative to other newly emerging place types of co-housing or 
cyber-café $(t(97)=-5.78, t(97)=-6.57$, respectively, $p<0.001)$, which did not differ from each other $(M \mathrm{~s}=3.89,4.05$; $\mathrm{SDs}=1.27$, 1.25 , respectively). On the other hand, nursing home was rated as a less familiar place compared to a hospital $(M=2.09, \mathrm{SD}=1.18$, $t(97)=-3.57, p<0.001)$, which in turn was seen as less familiar than a homelike place $(M=1.73, \mathrm{SD}=1.27, t(97)=2.31, p<0.02)$. Thus, a homelike place was rated as the most familiar together with the buffer item of school $(M=1.57, \mathrm{SD}=1.04)$.

The dendrogram obtained from the hierarchical cluster analysis revealed three clusters consisting of "most familiar everyday places" (i.e., school, a homelike place, hospital), "somewhat familiar places" (nursing home, an institutional place and assisted living), and the "unfamiliar, newly emerging places" (cyber-café, co-housing). Thus, both nursing home and assisted living were regarded as somewhat familiar places, the former being relatively more familiar than the latter.

\section{Attitudes Toward Assisted Living Facilities and Nursing Homes}

\section{Homelike and Institutional Place Representations}

By way of providing validity check for the measure, home was rated as most homelike, and nursing home as least so, whereas assisted living was seen as in between, but more similar to a homelike place than different (see Table I). In contrast, the institutional place descriptions were seen as most different from respondents' conceptions of home, and most similar to that of a nursing home, whereas that of assisted living was in between. Thus, as can be seen in Table I, on both indices, home and nursing home were characterized in opposite terms, while assisted living was conceived in between, but as having more homelike than institutional characteristics, all follow-up comparisons being significant at the 0.001 level.

\section{Impressions of Assisted Living Facilities}

In general, respondents' impressions of assisted living seemed to be "somewhat favorable" $(M=2.12, \mathrm{SD}=0.96)$. More specifically, $31 \%$ of the respondents were "very favorable"; $35 \%$ were "somewhat favorable"; $24 \%$ were "neither favorable, nor unfavorable"; and only $9 \%$ were "somewhat unfavorable". None of the respondents indicated being "very unfavorable". 


\section{TABLE I}

Means, standard deviations, and $F$-statistics involving differences between assisted living facilities (ALF), nursing homes (NH) and homes in terms of homelike and institutional representations and preferences to live in them in the future

\begin{tabular}{|c|c|c|c|c|c|c|c|}
\hline \multirow[t]{2}{*}{ Variables } & \multicolumn{2}{|l|}{ NH } & \multicolumn{2}{|l|}{ ALF } & \multicolumn{3}{|l|}{ Home } \\
\hline & $M$ & $\mathrm{SD}$ & $M$ & SD & $M$ & $\mathrm{SD}$ & $F^{\mathrm{a}}$ \\
\hline Homelike & $4.30_{\mathrm{a}}$ & 0.67 & $2.44_{b}$ & 0.85 & $1.79_{\mathrm{c}}$ & 0.88 & $253.51 * * *$ \\
\hline Institutional & $1.84 \mathrm{a}$ & 0.90 & $3.21_{\mathrm{b}}$ & 0.88 & $4.62_{c}$ & 0.55 & $310.96 * * *$ \\
\hline Preferences & $4.44 \mathrm{a}$ & 0.75 & $2.43_{\mathrm{b}}$ & 1.02 & $1.06_{\mathrm{c}}$ & 0.43 & $496.56 * * *$ \\
\hline
\end{tabular}

Note: Means with different subscripts are statistically different from each other at the 0.001 level according to Tukey Honestly Significant Difference (HSD) test.

${ }^{\mathrm{a}}$ Degrees of freedom $=2,194$.

$* * * p<0.001$.

\section{Preferences for Living in Assisted Living Facilities, Nursing Homes or Home}

As would be expected, almost everyone (97\%) was "very favorable" about living in their own homes. In contrast, most respondents felt "very unfavorable" $(60 \%)$ or "somewhat unfavorable" $(25 \%)$ about living in a nursing home, while most of the others were "neither favorable, nor unfavorable". On the other hand, preferences for assisted living seemed to fall between these two extremes of home and nursing homes. Specifically, more than half of the respondents reported feeling "somewhat" (45\%) to "very" (16\%) favorable about living in an assisted living. Another $27 \%$ seemed to feel neutral, while the rest were either "somewhat" or "very" unfavorable.

Thus, most respondents felt either somewhat favorable or neutral about living in an assisted living facility, while home and nursing homes were conceived as the most favorable and most unfavorable alternatives, respectively. As shown in Table I, results of an ANOVA indicated that the respondents felt significantly differently about living in these three place types, all comparisons being significant at the 0.001 level.

\section{Intercorrelations of Key Variables}

Table II shows intercorrelations between the variables considered. As can be seen in the lower half of Table II, familiarity with assisted 
TABLE II

Intercorrelations of key variables for assisted living facilities and nursing homes

\begin{tabular}{|c|c|c|c|c|c|}
\hline & 1 & 2 & 3 & 4 & 5 \\
\hline 1. Familiarity & - & & -0.18 & $-0.20^{*}$ & $0.44 * * *$ \\
\hline 2. Favorable impression & $0.27 * *$ & - & & & \\
\hline 3. Preferences & 0.19 & $0.43^{* * *}$ & - & $0.33^{* * *}$ & $-0.24^{*}$ \\
\hline 4. Homelike representation & $0.32 * * *$ & $0.44 * * *$ & $0.29 * * *$ & - & $-0.21 *$ \\
\hline 5. Institutional representation & -0.02 & $-0.29 * * *$ & -0.18 & $-0.43 * * *$ & - \\
\hline
\end{tabular}

Note: The lower half shows correlations for assisted living, while the upper half shows those for nursing homes with the exception of "favorable impression", data for which were not collected.

$* p<0.05 ; * * p<0.01 ; * * * p<0.001$.

living was positively associated with having a homelike representation and a favorable impression of it. In addition, familiarity showed a nonsignificant trend to be associated with considering living in one in the future $(p<0.06)$. Having a favorable impression of assisted living was positively associated with perceiving it as a homelike place, and preferring to live in one in the future, but negatively associated with an institutional representation of it. Similarly, preference to live in an assisted living facility was positively correlated with having a homelike representation, and showed a nonsignificant trend to be negatively correlated with having an institutional representation of it $(p<0.08)$. As would be expected, homelike and institutional representations of assisted living were negatively correlated with each other.

In contrast to assisted living, and as shown in the upper half of Table II, familiarity with nursing homes was negatively correlated with having a homelike representation, and positively correlated with having an institutional representation of it; as well as having a nonsignificant trend to be less likely to prefer living in one in the future $(p<0.08)$. Consistent with the results for assisted living, having homelike or institutional representations of nursing homes were negatively correlated with each other, and preference for living in one was positively correlated with the former, and negatively correlated with the latter representation. 
Relationships between Familiarity, Attitudes and Preferences for Assisted Living Facilities and Nursing Homes

Based on the results reported above, we proposed two versions of a three-factor model of relationships between familiarity, attitudes, and preferences regarding assisted living facilities (Figure 1(a)) and nursing homes (Figure 1(b)). We tested the proposed models by using LISREL. We found support for the models: $\chi^{2}(2, n=98)=1.71$, $p<0.43$, goodness of fit index $(\mathrm{GFI})=0.99$, adjusted goodness of fit index $(\mathrm{AGFI})=0.96$ for the model involving assisted living facilities, and $\chi^{2}(3, \mathrm{n}=98)=5.17, p<0.16, \mathrm{GFI}=0.97, \mathrm{AGFI}=0.91$ for the model involving nursing homes.

As the significant path coefficients in Figure 1(a) indicate, familiarity with assisted living facilities predicted both homelike representations and favorable impressions, which were positively associated. A favorable impression of assisted living facilities, in turn, predicted intention to live there in the future. Institutional representation of assisted living facilities did not appear to be a significant predictor in the model considered, and hence, was

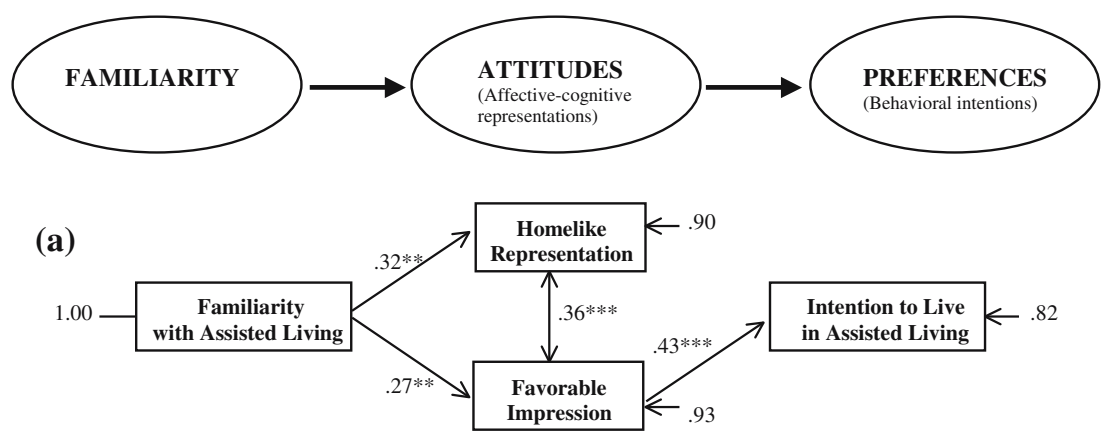

(b)

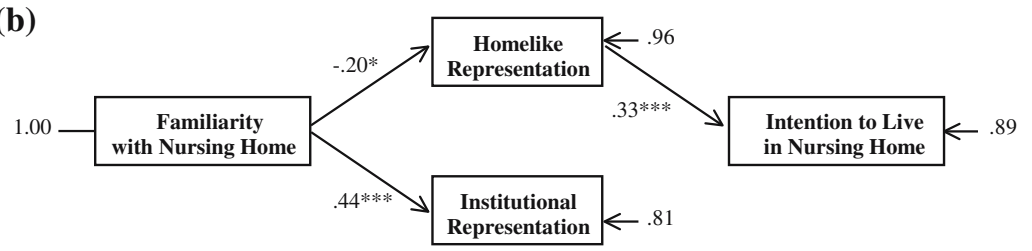

Figure 1. Significant path coefficients of the proposed model of relationships between familiarity, attitudes, and preferences regarding (a) assisted living facilities, and (b) nursing homes, tested using LISREL. ${ }^{*} p<0.05 ; * * p<0.01 ; * * * p<0.001$. 
dropped from the final model shown in Figure 1(a). In contrast, as the significant path coefficients in Figure 1(b) indicate, familiarity with nursing homes predicted institutional representations positively and homelike representations negatively. The homelike and institutional representations of nursing homes appeared to be distinct from each other, since the trend for a negative association did not reach significance. On the other hand, intention to live in a nursing home was predicted positively only by a homelike representation of it.

\section{DISCUSSION}

As mentioned above, one of the aims of the present study was to shed light on the controversy regarding the assessment of assisted living facilities by exploring respondents' related attitudes and preferences in comparison to those of nursing homes. In line with the related literature, respondents were found to be more favorable toward assisted living, which they conceived of as more homelike and less institutional than a nursing home (e.g., Imamoğlu and Imamoğlu, 1992; French and Mosher-Ashley, 2000; Kane, 2001). Most respondents not only had favorable impressions of assisted living, but they were also more favorable about living in this place type in the future as compared to a nursing home. Although having a positive impression of assisted living predicted being favorable about living in this type of accommodation in the future, their association was not very strong. This could be due to the fact that one may have a favorable impression of assisted living, but still prefer to live in one's own home, as one respondent reported in response to an open-ended question (Imamoğlu, 2002, unpublished): "I don't want to live anywhere but at home"; and yet another replied "not for me right now, but it's a good thing to have available". Thus, most respondents regarded assisted living as a good or at least neutral alternative, and regarded it as preferable to a nursing home.

As stated before, one aim of this study was to explore how nursing homes and assisted living facilities are represented in terms of certain place descriptors. The descriptors used were selected on the basis of the related literature (as has been noted in the Methods section), 
which indicates that some descriptors tend more likely to be associated with a homelike place, and some with an institutional place. However, our findings indicated that "homelike" and "institutional" descriptors should not be regarded as opposite, but as separate dimensions. Although they were negatively correlated, the correlations were not strong, and in fact they were much weaker than one might assume, particularly in the case of nursing homes $(r=-0.21$ for nursing homes and -0.43 for assisted living). Hence, the homelike and institutional representations of nursing homes did not appear to be well-integrated, as considered further in the paper.

The second aim of the present study was to explore the impact of familiarity on attitudes and preferences regarding assisted living facilities and nursing homes. Results concerning the degree of familiarity with different place types indicated that respondents in general tended to regard assisted living facilities and nursing homes similarly, as being "somewhat familiar places", although they tended to be more familiar with the latter compared to the former. However, the impact of familiarity on attitudes seemed to be rather different for assisted living facilities and nursing homes. Respondents who were more familiar with assisted living tended to have more positive attitudes toward it. Specifically, those who were more familiar with assisted living tended to have more homelike representations and more favorable impressions of it. Thus, results concerning the impact of increased familiarity with assisted living facilities seem to be consistent with the mere exposure effect (Zajonc, 1968). As referred to in the Introduction, the mere exposure effect states that the more people are exposed to an initially unobjectionable stimulus, the more likely they are to like it. As has been noted, the mere exposure effect has been found to be valid for different types of stimuli, such as, meaningful or nonsense words, photographs, real persons/objects and auditory material (Bornstein, 1989; Zajonc, 2001). Present findings concerning assisted living indicated that it is also applicable to place types that one tends to be positive or neutral toward.

In contrast, increased familiarity with nursing homes seems to predict stronger institutional and weaker homelike representations of them. As expected, present findings concerning nursing homes appear to be consistent with those studies that have indicated that the mere exposure effect does not seem to work for stimuli which are initially regarded in negative terms (e.g., Perlman and Oskamp, 1971; Swap, 
1977). Thus, in congruence with past findings about people or objects, present results imply that increased familiarity with an initially unfavorable place type, such as nursing homes may enhance those unfavorable evaluations.

Speculating about the underlying reasons for the above-noted relationship between familiarity and attitudes, one may refer to the idea of exemplars (i.e., specific cases experienced) vs. prototypes (i.e., generalized abstractions from prior experiences) in schema theory (see Fiske and Taylor, 1991). In their judgments, people with less experience with a place type may be relying on just the exemplars they have been exposed to, whereas those with more experience, and hence more familiarity, may have also developed prototypes that they could refer to. For instance, respondents who were less familiar with assisted living facilities or nursing homes might have been relying on their impressions from their limited experiences or few examples they have visited. However, those more familiar might have been exposed to various such facilities that might have enabled them to develop prototypes, which may tend to amplify their initial (either favorable or unfavorable) attitudes regarding specific incidents.

Thus, although the impact of familiarity may seem to be different for assisted living facilities and nursing homes, the basic psychological mechanism underlying these two cases may be similar in that familiarity may be serving to amplify the existing dominant affectivecognitive responses regarding them. Hence, in the case of (the somewhat favorable) assisted living facilities, the more dominant homelike representations may get strengthened, whereas in the case of (the rather unfavorable) nursing homes, the more dominant institutional representations may be amplified through increased familiarity. As such, present findings are not totally congruous with Zajonc's (1968) assertion that familiarity leads to liking. However, present results seem to be consistent with his initial statement that "mere repeated exposure of the individual to a stimulus is a sufficient condition for the enhancement of his attitude toward it" (Zajonc, 1968, p.1, italic added), when enhancement is understood as strengthening of the initial attitudinal responses.

Although we have interpreted the present results in terms of the impact of familiarity on attitudes, it should be noted that our results do not necessarily indicate causality. In fact, some studies about the mere exposure effect refer to the "good-is-familiar" phenomenon in 
that the positive valence of a stimulus seems to increase its perceived familiarity even in the absence of prior exposure (Monin, 2003; Garcia-Marques et al., 2004). For example, positive words were found to feel more familiar than negative or neutral ones. Monin refers to the warm glow heuristic of using positive affect to infer familiarity. This explanation may also be applicable to the present findings regarding assisted living in that those respondents who had more homelike representations of assisted living might have rated themselves as more familiar with it. However, by the same logic, one might also have expected the ratings of familiarity with nursing homes to increase in parallel to those of homelike representations, and to decrease in parallel to institutional representations; however, just the opposite was found. Thus, the warm glow heuristic explanation does not seem to explain present findings regarding nursing homes.

Results suggested a model to explain the relationship between familiarity, attitudes and preferences. This three-factor model proposes that increased familiarity with a place type (or possibly some other stimulus) may serve to strengthen the dominant affective-cognitive representations or the positive or negative attitudinal responses toward it, which then may have an impact on the related preferences or behavioral intentions. Accordingly, as noted above, familiarity may serve to amplify a positive attitude or representation if that happens to be dominant, as in the homelike representation of assisted living, or it may serve to strengthen a negative attitude or representation that may happen to be dominant, as in the institutional representation of nursing homes.

Unlike familiarity, which seems to be associated with the dominant attitudinal responses (either positive or negative), preferences appear to be associated with the positive attitudinal responses. Specifically, preferences to live in assisted living facilities and nursing homes both seem to be predicted by the favorable homelike representations. Institutional representations seemed to have no effect in predicting intention to live in either place type. Thus, for both the positively and negatively valenced place types, preferences seem to be predicted by the positively valenced aspects. This seems to be the case even if the positively and negatively valenced aspects do not seem to be well integrated, but tend to be either distinct or very weakly associated as in the case of nursing homes. 
Results indicated that respondents' attitudes regarding assisted living seem to be more integrated in a consistent manner in that the favorable homelike representations tend to be negatively associated with institutional representations. On the other hand, the homelike and institutional representations regarding nursing homes do not seem to be closely associated, hence giving the impression of a rather fragmented attitude. Thus, increased familiarity with nursing homes seems to predict stronger institutional representations, whereas preferences seem to be predicted by homelike representations of nursing homes; and these two types of representations tend to be rather distinct from each other.

In general, the present model proposes that attitudes tend to mediate between familiarity and preferences. Familiarity did not predict preferences in either the analysis involving assisted living or that involving nursing homes. Accordingly, the impact of familiarity on preferences does not seem to be direct, but indirect through the mediating role of related attitudes. In the case of assisted living, homelike (rather than institutional) representations seem to serve as the mediators, whereas in the case of nursing homes, both institutional and homelike representations seem to be involved in the mediation process. Thus, it is suggested that when integrated (generally positive) attitudes are considered, only positive affectivecognitive representations seem to mediate between familiarity and preferences. On the other hand, when less integrated (generally negative) attitudes are considered, it is suggested that both negative and positive representations tend to mediate between familiarity and preferences in the form of two rather distinct processes. Basically, the first process links familiarity with negative representations, while the other links positive representations with preferences.

The results of this study support the assertions of Ajzen and Fishbein (Ajzen, 1991; Ajzen and Fishbein, 1980) concerning the link between attitudes and behavioral intentions. According to their theory of reasoned action (or theory of planned behavior as it was called later), behavioral intentions, which are regarded as the best single predictor of an individual's behavior, are strongly influenced by the person's (a) attitudes toward the behavior in question, (b) beliefs about others' evaluations or subjective norms, and (c) perceived behavioral control, that is, perceived ease or difficulty of accomplishing the behavior. In the present study, only the role of attitudes 
toward different place preferences has been explored. Future investigations are advised to consider also the influence of subjective norms and perceived behavioral control on behavioral intentions regarding housing preferences.

Before concluding, some limitations of the study need to be considered. First, as has been noted, a convenience sample was used in the survey. This was necessitated by problems of access to respondents, as well as the respondents' ability and willingness to participate in the study. Therefore, one needs to be cautious in generalizing the results to the larger population. To further explore the generalizability of the findings, future studies can explore possible variations in the responses of, for instance, social workers working with older adults, or samples from different cultures with different outlooks toward old age and institutional living. Although support was found for the proposed three-factor model, in future studies, the model should be tested using larger samples, as suggested by Tabachnick and Fidell (2001). Additionally, because the emphasis of the present study was on assisted living facilities, favorability measures were not obtained for nursing homes; hence, future investigators are advised to obtain favorability measures for all place types, since that variable appeared to be the strongest predictor of preferences for assisted living facilities. Future studies can also explore the degree to which the present findings can be generalized to other new place types such as co-housing. As another limitation of the present study, it should be noted that the predictors specified in the paper do not necessarily imply causality; for instance, familiarity measures were based on verbal reports rather than experimental manipulation. However, convergence of the findings with experimental studies related to the mere exposure effect (e.g., Zajonc, 2001) seems to support the plausibility of a causal explanation.

In conclusion, the contributions of the present study are 2-fold: First, it demonstrated that respondents' attitudes toward assisted living facilities were generally positive, particularly compared to nursing homes. Second, it demonstrated different types of relationships between familiarity, attitudes and preferences regarding assisted living facilities and nursing homes. In doing so, it provided evidence to indicate that mere exposure effect can be applicable to initially favorable place types, which to our knowledge has not been reported before. Furthermore, the study suggested that increased familiarity 
with a place type tends to enhance the existing attitudes toward it rather than merely breeding liking as stated by the mere exposure effect. By extrapolating from the findings on the impact of familiarity on evaluations of assisted living facilities and nursing homes, it can be concluded that they would be conceived of in even more differentiated terms in the future, as people become more familiar with them. Thus, assisted living appears to be an acceptable alternative, the favorability of which might be expected to increase in time.

\section{ACKNOWLEDGEMENTS}

The present study is based on an extended analysis of the data collected for a doctoral dissertation conducted at University of Wisconsin-Milwaukee by the first author, who expresses his thanks to Professor Jerry Weisman for his guidance, and Fulbright Research Commission, Turkish Science and Research Council (TUBITAK), and the Graduate School of University of Wisconsin-Milwaukee for providing partial financial support.

\section{REFERENCES}

Ajzen, I.: 1991, 'The theory of planned behavior: Special issue: Theories of cognitive self-regulation', Organizational Behavior and Human Decision Processes 50, pp. $179-211$.

Ajzen, I. and M. Fishbein: 1980, Understanding Attitudes and Predicting Social Behavior (Prentice-Hall, Eaglewood Cliffs, NJ).

Ball, M. M., F. J. Whittington, M. M. Perkins, V. L. Patterson, C. Hollingsworth, S. V. King and B. L. Combs: 2000, 'Quality of life in assisted living facilities', Journal of Applied Gerontology 19(3), pp. 304-325.

Becker, M., P. Stiles and L. Schonfeld: 2002, 'Mental health service use and cost of care for older adults in assisted living facilities: Implications for public policy', Journal of Behavioral Health Services and Research 29(1), pp. 91-98.

Bornstein, R. F.: 1989, 'Exposure and affect: Overview and meta-analysis of research, 1968-1987', Psychological Bulletin 106, pp. 265-289.

Brummett, W.: 1997, The Essence of Home: Design Solutions for Assisted Living Housing (Van Nostrand Reinhold, New York).

Carp, F. M.: 1966, A Future for the Aged (University of Texas, Austin).

Day, K., D. Carreon and C. Stump: 2000, 'The therapeutic design of environments for people with dementia: A review of the empirical research', Gerontologist 40(4), pp. $397-416$. 
Dobbs, D.: 2004, 'The adjustment to a new home', Journal of Housing for the Elderly 18(1), pp. 51-71.

Fiske, S. T. and S. E. Taylor: 1991, Social Cognition, 2nd edition. (McGraw-Hill, New York).

French, E. M. and P. M. Mosher-Ashley: 2000, 'College students' attitudes toward residential care facilities', Educational Gerontology 26(6), pp. 583-603.

Garcia-Marques, T., D. M. Mackie, H. M. Claypool and I. Garcia-Marques: 2004, 'Positivity can cue familiarity', Personality and Social Psychology Bulletin 30(5), pp. 585-593.

Grundy, E.: 1983, 'Demography and old age', Journal of the American Geriatrics Society 31 , pp. 325-332.

Gubrium, J. F.: 1975, Living and Dying at Murray Manor (St. Martin's, New York).

Habell, M.: 2001, 'The evolution of 'Close Care' as user-led care of the elderly in the UK', Journal of the Royal Society for the Promotion of Health 121(3), pp. 165173.

Hauser, P. M.: 1976, 'Aging and world wide population change', in R. H. Binstock, and E. Shanas (eds.), Handbook of Aging and the Social Sciences (Von Nostrand, New York), pp. 59-86.

Imamoğlu, C.: 2002, Toward an Understanding of Place Schema: Societal and Individual-Level Representations of Assisted Living. Unpublished doctoral dissertation (University of Wisconsin, Milwaukee).

Imamoğlu, C.: 2005, Assisted Living as a New Place Schema. Manuscript in preparation (Bilkent University, Ankara, Turkey).

Imamoğlu, E. O. and V. Imamoğlu: 1992, 'Life situations and attitudes of the Turkish elderly toward institutional living within a cross-cultural perspective', Journal of Gerontology: Psychological Sciences 47(2), pp. 102-108.

Imamoğlu, E. O. and N. Kılıç: 1999, 'A social psychological comparison of the Turkish elderly residing at high or low quality institutions', Journal of Environmental Psychology 19, pp. 231-242.

Johnson, C. L. and L. A. Grant: 1985, The Nursing Home in American Society (Johns Hopkins University, Baltimore).

Kane, R. A.: 2001, 'Long-term care and a good quality of life: Bringing them closer together', Gerontologist 41(3), pp. 293-304.

Kane, R. A. and K. B. Wilson: 1993, Assisted Living in the United States: A New Paradigm for Residential Care for Frail Older Persons? (American Association of Retired Persons, Washington DC).

Langer, E. J. and J. Rodin: 1976, 'The effects of choice and enhanced personal responsibility for the aged: A field experiment in an institutional setting', Journal of Personality and Social Psychology 34, pp. 191-193.

Lawton, M. P. and J. Cohen: 1974, 'The generality of housing impact on the wellbeing of older people', Journal of Gerontology 29, pp. 194-204.

Marsden, J. P.: 1999, 'Older persons' and family members' perceptions of homeyness in assisted living', Environment and Behavior 31(1), pp. 84-106.

Mollica, R. L., K. B. Wilson, B. S. Ryther and H. J. Lamarche: 1995, Guide to Assisted Living and State Policy (University of Minnesota, Minneapolis).

Monin, B.: 2003, 'The warm glow heuristic: When liking leads to familiarity', Journal of Personality and Social Psychology 85(6), pp. 1035-1048. 
Moreland, R. L. and S. R. Beach: 1992, 'Exposure effects in the classroom: The development of affinity among students', Journal of Experimental Social Psychology 28, pp. 255-276.

Perlman, D. and S. Oskamp: 1971, 'The effects of picture content and exposure frequency on evaluations of negroes and whites', Journal of Experimental Social Psychology 7, pp. 503-514.

Peskin, M. and F. N. Newell: 2004, 'Familiarity breeds attraction: Effects of exposure on the attractiveness of typical and distinctive faces', Perception 33(2), pp. 147-157.

Regnier, V.: 1994, Assisted Living Housing for the Elderly: Design Innovations from the United States and Europe (Van Nostrand Reinhold, New York).

Rodin, J. and E. J. Langer: 1977, 'Long-term effects of a control-relevant intervention with the institutionalized aged', Journal of Personality and Social Psychology 35, pp. 897-902.

Rowland, K. F.: 1977, 'Environmental events predicting death for the elderly', Psychological Bulletin 84, pp. 349-372.

Schooler, K. K.: 1976, 'Environmental change and the elderly', in I. Altman, and J. F. Wohlwill (eds.), Human Behavior and Environment (Plenum, New York), pp. 265-298.

Schulz, R.: 1976, 'Effects of control and predictability on the physical and psychological well-being of the institutionalized aged', Journal of Personality and Social Psychology 33, pp. 563-573.

Schulz, R. and B. H. Hanusa: 1980, 'Experimental social gerontology: A social psychological perspective', Journal of Social Issues 36, pp. 30-46.

Schwarz, B.: 1999, 'Assisted living: An evolving place type', in B. Schwarz, and R. Brent (eds.), Aging, Autonomy, and Architecture: Advances in Assisted Living (The Johns Hopkins University Press, Baltimore, MD), pp. 185-206.

Schwarz B. and R. Brent (eds.): 1999, Aging Autonomy and Architecture: Advances in Assisted Living (The Johns Hopkins University Press, Baltimore, MD).

Sheehan, N. W. and C. E. Oakes: 2003, 'Bringing assisted living services into congregate housing: Residents' perspectives', Gerontologist 43(5), pp. 766-770.

Slivinske, L. R. and V. L. Fitch: 1987, 'The effect of control enhancing interventions on the well-being of elderly individuals living in retirement communities', Gerontologist 27, pp. 176-181.

Steinhauer, J.: 2001 (February 12), 'As assisted living centers boom, calls for regulation are growing', New York Times, p. A1.

Swap, W. C.: 1977, 'Interpersonal attraction and repeated exposure to rewarders and punishers', Personality and Social Psychology Bulletin 3, pp. 248-251.

Tabachnick, B. G. and L. S. Fidell: 2001, Using Multivariate Statistics (Allyn and Bacon, Boston).

Wilson, K. B.: 1990, 'Assisted living: The merger of housing and long term care services', Long Term Care Advances 1(4), pp. 2-8.

Zahn, M.: 2001 (August 26), 'Lapses lead to deaths in assisted living care', Milwaukee Journal Sentinel, p. 1A.

Zajonc, R. B.: 1968, 'Attitudinal effects of mere exposure', Journal of Personality and Social Psychology Monograph Supplement 9, pp. 1-27.

Zajonc, R. B.: 2001, 'Mere exposure: A gateway to the subliminal', Current Directions in Psychological Science 10(6), pp. 224-228. 
Zavotka, S. L. and M. H. Teaford: 1997, 'The design of shared social spaces in assisted living residences for older adults', Journal of Interior Design 23(2), pp. $2-16$.

Zimmerman S. I.: 2000, 'Policies and practices in assisted living', The Gerontologist: 53rd Annual Scientific Meeting. Linking Research to Policy, Practice, and Education: Lessons Learned, Tasks Ahead 40, pp. 209-210.

Department of Interior Architecture and Çağri Imamoğlu Environmental Design

Bilkent University

Ankara 06800

Turkey

E-mail: icagri@bilkent.edu.tr

Department of Psychology

E. Olcay Imamoğlu

Middle East Technical University

Ankara 06531

Turkey 